\title{
Parkour as Health Promotion in Schools: A Qualitative Study Focusing on Aspects of Participation
}

\author{
Grabowski, D..$^{1, *} \&$ Thomsen, S.D. ${ }^{1}$ \\ ${ }^{1}$ Health Promotion Research, Steno Diabetes Center, 2820 Gentofte, Denmark \\ *Corresponding author: Health Promotion Research, Steno Diabetes Center, Niels \\ Steensens Vej 8, 2820 Gentofte, Denmark
}

Received: September 23, 2014 Accepted: October 20, 2014 Published: November 14, 2014

doi:10.5296/ije.v6i4.6343 URL: http://dx.doi.org/10.5296/ije.v6i4.6343

\begin{abstract}
In this paper we highlight the potential role of parkour in school-based health promotion for children and adolescents. The popularity of parkour has increased significantly in recent years and has attracted a lot of new participants. Health promotion initiatives in schools face challenges, when it comes to generating a high level of participation among children and adolescents. Parkour has only sporadically been introduced to the school setting, and it is therefore relevant to study whether parkour contains the elements that can generate a high level of participation within health promotion activities in school. The paper reports on an empirical study of how parkour generates different kinds of participation. The paper provides health practitioners with important knowledge about why and how it is important to use parkour in school health promotion in order to provide participatory conditions that create a significant health promoting effect for all adolescents - not just for those who are already healthy.
\end{abstract}

Keywords: parkour, health, health education, participation, children, adolescents 


\section{Introduction}

The role of participation in health promotion and health education for children and adolescents is an important and much studied subject. Most research agrees on the fact that the success of health education and health promotion initiatives is closely linked to the achieved level of participation (Jensen, 1997; Jensen \& Simovska, 2005). However, health promotion initiatives in schools still face challenges when it comes to generating a high level of participation among children and adolescents (e.g. Sinclair, 2004; Simovska, 2007).

Parkour is an activity that might have potential as a participatory health promotion activity in school. The popularity of parkour has increased enormously in recent years and has attracted a lot of new participants among young people (e.g. Angel, 2011; Gilchrist \& Wheaton, 2011; Clegg \& Butryn, 2012). Parkour has only sporadically been introduced to the school setting (Gilchrist \& Wheaton, 2011), and it is therefore highly relevant to study whether parkour contains the elements that can generate a high level of participation within health promotion activities.

It is often found difficult to present health education, physical education and health-information in ways that seem relevant, authentic and meaningful to children and adolescents (Peters et al., 2009; Petraglia, 2009; Wistoft, 2010; Grabowski \& Rasmussen, 2014). Children and adolescents request activities where they can participate actively and where they can relate the content of the activities and the presented information to their own lives. The activities and information has to seem relevant and meaningful to them (Wistoft, 2010).

Parkour is an emerging lifestyle sport and physical discipline where the aim is to move as smoothly, quickly and effectively from one location to another. This is done by overcoming obstacles, both physical and emotional, and on the way using only the body - this may involve climbing, vaulting, jumping and balancing (e.g. Ameel \& Tani, 2012; Angel, 2011; Gilchrist \& Wheaton, 2011; Saville, 2008; Wheaton, 2004). It is also an activity that involves learning how to overcome one's fears and limitations by mastering both the body and the mind (Angel, 2011). Parkour has its own unique set of values that in many ways differ from both traditional and other lifestyle sports (Gilchrist \& Wheaton, 2011). Parkour is a non-competitive activity. Practitioners of parkour, or traceurs as they call themselves, do not compete against each other; instead parkour is about challenging yourself and your level of skill both physically and mentally (Gilchrist \& Wheaton, 2011; Angel, 2011). It is effort and attitude that are rewarded instead of ability. The parkour-community is characterised as very non-hierarchical, inclusive and responsible. The inclusive aspect of parkour is visible in the way beginners and outsiders are supported and embraced in the parkour-community (Gilchrist \& Wheaton, 2011; Clegg \& Butryn, 2012). Another important value in parkour is that it is less rule-bound than most sports. Even though there are specific techniques, parkour does not have a distinct set of rules or objectives that needs to be followed (Gilchrist \& Wheaton, 2011).

Parkour has received relatively little attention as a research topic so far (Brunner, 2011), but it is beginning to attract increasing academic interest (Ameel \& Tani, 2012). A lot of the 
previous studies of parkour have focused on how traceurs see, use and experience the environment differently than other people. Atkinson (2009) has interpreted parkour as a new version of flâneurism, because traceurs use the urban environment in innovative and playful ways that are different from accepted norms and rhythms in the cities. Atkinson also suggests that parkour can be seen as a modern form of social protest, because parkour questions urban spatial boundaries, addresses environmental concerns and disrupts the flow of the cities' commercial spaces (Atkinson, 2009). Bavinton (2007) has examined one of parkour's key values of turning obstacles into opportunities, and concludes that traceurs reinterpret constraints instead of removing them, and thereby use the space in personal and creative ways. One of Bavinton's conclusions is that the traceurs' interaction with constraints contributed to their sense of agency as individuals. Like Atkinson, Saville (2008) proposes that parkour can be characterised as a kind of play with architecture and argues that this play is characterised by an array of fears. Fear can, instead of just restricting movement, sometimes encourage imaginative and playful forms of movement, and, according to Saville, in parkour fear is to be considered a playmate rather than a coping strategy. Kidder (2013) also focuses on fear in relation to parkour, but with a different perspective than Saville. According to Kidder there is an ever-present risk of physical injury in parkour, and therefore a great deal of parkour revolves around fear. Kidder describes parkour as a form of urban adventurism, where the adventure revolves around what Kidder calls 'rites of risk' (i.e. actions that put one's corporeal self on the line) and 'rituals of safety' (i.e. following a set of progressive steps).

According to Ameel and Tani (2012) traceurs get unique and embodied relationships with their daily surroundings, because they attach emotions to the surroundings. Traceurs get a bigger sense of belonging to their immediate environment, because they ascribe new meanings to their everyday spaces. Their research suggest that traceurs develop 'parkour eyes', which means that they see their environment in a remarkably different way than most other people, which creates possibilities for innovative movement. Gilchrist and Wheaton have examined the use of parkour in policy interventions with different purposes e.g. reducing antisocial behaviour, social inclusion and increasing physical activity. Their research show that parkour, in specific circumstances, can contribute to physical health, well-being, community and civic engagement among groups who normally do not participate in traditional sports and physical activity.

As this overview of existing research on parkour shows, the research represents several different fields. Only Gilchrist and Wheaton (2011) examine parkour as a pedagogical activity and marginally address the issues of participation and health in connection with parkour. However, their focus is much wider as they have examined how and why parkour has been embraced in different policy contexts, such as sport, art and education.

The participation of children and adolescents is an important topic in research areas relating to both education and health (e.g. Mager \& Nowak, 2012; Wilson, 2009; Simovska, 2007; Sinclair, 2004). According to Simovska (2007) it is possible to differentiate between two kinds of definitions of participation. The first one understands participation in the sense of 'taking part in' or 'being present'. This understanding refers to the involvement of children 
and adolescents in pre-designed activities, where their influence on content and form is not taken into consideration. The second definition understands participation in the sense of children and adolescents having an impact on things that are relevant and important to them. This understanding is related to notions such as empowerment, ownership and self-determination.

Hart (1992) notes that participation varies with individual characteristics and with the context. Children and adolescents have different motivations, capacities and potentials for participation (Hart, 1992; Sinclair, 2004; Nordin, et al. 2010). According to Hart it is important to maximise the opportunity for any child or adolescent to choose to participate at the highest level of their ability (Hart, 1992).

Participation of children and adolescents can occur in many ways ranging from token to genuine participation (Hart, 1992; Simovska, 2004 \& 2007; Jensen \& Simovska, 2005). Token participation focuses on acquisition of curriculum content that has to be learned, accepted and used and targets individuals. The desired outcomes are predetermined behaviour results. Genuine participation on the other hand, focuses on knowledge acquisition through reflections, personal meanings and social constructions. The desired outcomes are to encourage autonomy, critical consciousness and responsible freedom with regard to health matters. Genuine participation targets individuals inseparable from their living environments (Simovska, 2004 \& 2007). According to Simovska, genuine pupil participation is an important factor in making learning personally meaningful, as it makes it possible for children and adolescents to create ownership of the learning process because their ideas and interests are taken into account (Simovska, 2004).

That the pupils experience real influence and that their ideas are being taken seriously and acted upon are other important factors (e.g. Jensen \& Simovska, 2005; Wilson, 2009). This is also important in order for the children and adolescents to feel a sense of ownership of the activity that they participate in. If children and adolescents do not develop ownership, it is not likely that the activities will lead to changes in their practice or behaviour.

The concept of participation has not been used to any great length in studies of parkour. Little is known about parkour as a school-based health promotion activity, and the main objective of this article is therefore to study whether parkour as a school activity contains possibilities to generate participation among children and adolescents.

\section{Methods}

\subsection{The context of the study}

In order to know more about parkour as a health promotion activity and its potentials for generating participation, this study explores parkour in three different empirical contexts:

1) Organised and regular parkour training: A private organisation offering organised training in parkour. The training is divided into different classes depending on age. The instructors are young people who have practiced parkour for several years and who all are 
certified ADAPT-instructors(Note 1).

2) Parkour workshops: These are school classes participating in parkour workshops. The instructors who teach at the workshops are from the same organisation as above. The workshops are primarily directed at children and adolescents who do not have detailed knowledge about parkour and who try parkour for the first time.

3) Parkour in physical education in primary school: This is children being taught about parkour in physical education by their teachers who have taken a parkour course for schoolteachers who wish to introduce parkour in primary school. The aim of the teacher-course is to make sure that the introduction of parkour in the primary school happens in a safe manner that stays true to the values of parkour.

\subsection{Data collection}

All in all the data material consists of 25 semi-structured group interviews with a total of 90 children and adolescents and 6 semi-structured individual interviews with teachers. The circumstances surrounding the data collection differed for each of the three contexts. Nevertheless, both the main points concerning challenges and barriers as well as some other issues concerning the practicalities of the interviews are similar enough to be described as a whole.

\subsection{Group interviews with children and adolescents}

In each of the empirical contexts, the children and adolescents were asked to volunteer for interviews. From the volunteers three to four children or adolescents were chosen to partake in each group interview.

We have conducted:

- 10 semi-structured group interviews with children and adolescents aged 6 to 18 , who attend organised parkour training regularly.

- 7 semi-structured group interviews with adolescents aged 13 to 14 , who have participated in parkour workshops.

- Eight semi-structured group interviews with children aged 9 to 10 , who have received parkour-training by their teacher in physical education.

The interviews lasted as long as the children and adolescents had something to say and could maintain a reasonable level of concentration. Most of the interviews lasted around 30 minutes. The main themes in the interview guides were:

(1) What do you think about parkour?

(2) What did you think about the lessons/workshop/practice in parkour?

(3) How were the lessons/workshop/practice in parkour organised?

(4) What did you think of the instructor/teacher in parkour? 
(5) What did you learn from the lessons/workshop/practice in parkour?

(6) Are you physically active in your everyday life?

These main themes were dealt with in different sets of questions depending on the empirical context and the age of the children/adolescents interviewed.

\subsection{Individual interviews with teachers}

We conducted four semi-structured interviews with teachers who accompanied the children to workshops and two interviews with teachers who introduced parkour in physical education after having attended the instructor-course.

The interviews lasted as long as the teachers had something to say. Most of the interviews lasted approximately 30 minutes. The main themes in the interview guides were:

- What did you think about parkour in general?

- How was the lessons/workshop in parkour organised?

- What did the pupils get out of and learn from the lessons/workshop in parkour?

- How was it to teach parkour?/ What did you think of the instructors?

- How does parkour fit into the everyday health education in school?

- Are these pupils physically active/healthy?

\section{Data analysis}

The group interviews with the children and adolescents and the individual interviews with the teachers are given equal priority in the analysis. All interviews were transcribed and iteratively analysed and categorised using Rasmussen's guidelines for content analysis which, being a combination of hermeneutics and constructivism, manages to be empirically true and complexity oriented at the same time (Rasmussen, 2004). Radical hermeneutics focuses on keeping a perpetual balance between theory, method and data by acknowledging this as an interconnected process that requires a constant focus on how all the elements influence each other. The use of radical hermeneutics also entails a constant fluctuation between analysis and interpretation. This means that it is sometimes necessary to present interpretive aspects while presenting the findings.

Radical hermeneutics entails three steps of data analysis, The first step involves a reading of the data with a view to observing how specifically selected guiding differences or interpreter's differences are observed in the data material. This observation in itself constitutes an interpretation rather than a description. Its purpose is to reduce complexity in the data. Elements within the scope of the differences selected by the interpreter are extracted from the data. The second step involves making these elements the subject of interpretation as an observation of the difference(s) employed. The third step involves an interpretation of the sum of these differences (Rasmussen 2004). 
In this analysis, the analytical process was developed in the following steps: The first step focused on searching for elements that related to the children's and adolescents' participation in the three parkour-activities. This first selective interpretation reduces the complexity of the empirical data significantly. The second step is the analysis and interpretation of this selected empirical data. This step disclosed four themes related to participation, which are presented in the findings-section. The third step is the separate analysis and interpretation of these four themes. Doing the analysis and interpretation in these steps makes it easy to keep track of the choices and distinctions that are made throughout the process. This makes the process transparent and secures a high level of methodological reflexivity.

\section{Ethics}

There is no formal agency for the assessment and approval of interview-based studies in Denmark. The study complies with the second revision of the Declaration of Helsinki on ethical issues, and all of the informants participated after informed consent.

\section{Findings}

The analysis of the data revealed four independent yet still interdependent themes, with direct relevance for the children's and adolescents' participation. In the following sections, we present the most significant results in each of these themes.

\subsection{Flexibility}

In most of the interviews it is significant that parkour is seen as very flexible. This played a central role in generating participation among the children and adolescents. This flexibility creates a constant potential for changing the level of difficulty or the general setup in the exercises and activities. A teacher, who observed a parkour workshop, comments on this:

"Well the workshop was organised in such a way that there were exercises at all levels of difficulty. Everyone could do something that was challenging for them. And they could just continually add to the level of difficulty and make it higher or crazier and so on. And it wasn't like half of them suddenly sat down, because they couldn't participate." (Teacher of adolescents 14-15 years of age)

All of the teachers, children and adolescents emphasised the different levels of difficulty as an advantage in connection with the opportunities to participate in the parkour-activities. Another advantage they all emphasised was the level of freedom. They all felt that they decided the level of difficulty in the exercises themselves. They also stressed it as an advantage that they could do the exercises and overcome the challenges in different ways without doing them wrong.

The teachers, the children and the adolescents all emphasised the instructors' genuine interest in what the children and adolescents were saying and their ability to listen to their ideas and use them actively: 
"I thought they were good instructors, because they listened. If you had an idea, they listened to it and then they quickly decided whether it was a good idea or a bad idea. Would you hurt yourself by doing it? - no. Would you learn from it? - yes. All right, we can try that. It was really nice that they also listened to you." (Boy, 13 years old, workshop participant)

In the workshops with professional instructors, ideas brought up by the children and adolescents could be tried out. The same kind of flexibility was not present when it was schoolteachers who taught the children in physical education.

\subsection{Factors of inclusion and exclusion}

Parkour managed to generate participation among almost all the children and adolescents also among those that normally did not participate in physical education and those who normally did not have any motivation or interest in school-related activities. A teacher described how the workshop in parkour revealed a new side of one of her pupils. Normally this 13 year old girl did not participate and physical activities and gave up very easily:

"The instructor really seized the opportunity - they just continued, and then she actually proved that she could do all of those things. She could climb that wall, she could jump, she could do it all, and that was really good for her." (Teacher)

Several teachers suggested that parkour's ability to engage pupils, who have previously shown very little interest in sports and physical activity, may have something to do with parkour being different from traditional forms of sport and physical activity.

Two boys, who attend organised parkour training regularly, described how they see parkour as a different kind of sport:

"It's not like you aim for first prize or anything like that. There's no competition. It's more like we're a team. We do it together."

"We begin and finish together."

"That's the cool thing about it, I think. And I'm actually a very competitive person. I think this sport is something special" (Boys, 13 and 17 years old)

This principle of solidarity, that these boys mention, is something that a lot of pupils mention as significantly different from all other sports they have tried. Two girls, who participated in a workshop, liked this aspect of solidarity and it definitely heightened their level of participation:

"You didn't have to just stand around and wait for the others. You had to do a demanding leg-exercise while you waited, and that was really nice. You showed the others respect by saying; we are waiting for you actively and things like that. I liked that".

"Yes, me too. Nobody felt that they were really bad at it or left behind. So everybody was somehow on the same level"

(Girls, 13 years old) 
Most of the children and adolescents already knew a little about parkour before participating in the activities. Therefore a lot of them entered the parkour-activities with expectations about what they were going to do. Many of them expected parkour to be about doing dangerous stunts. These expectations may have influenced their interest and motivation for participating in parkour. The empirical data suggest that the professional instructors were good at listening to and helping the children and adolescents when they felt insecure or afraid. A teacher talks about this:

"They really listened and sincerely wanted to understand what the reason was [for not wanting to participate in a given exercise]. They listened and then they patiently explained the risks and the techniques in a very convincing way... and they were really calm and friendly and then they actually got them to do the exercises." (Teacher of 14-15 year olds, at workshop)

This inclusive and emphatic approach to parkour training is most evident in the workshops and in the organised training.

\subsection{Various physical potentials}

In an activity like parkour, the different physical capabilities of the children's and adolescents play a significant role in relation to barriers and potentials for participation.

A lot of the teachers commented on whether or not the children and adolescents lived up to expectations:

"Well, you had the computer boys - and I was not happy to see that. It was frightening to see what they couldn't do, and I think it also came as a bit of a surprise to them... On the other hand, I knew that the girls would be good at it. They are very physically active girls" (Teacher of 13-14 year olds, at workshop)

Another teacher, who observed a workshop, experienced the how the expected physical activity hierarchies were actually challenged in the parkour-activities:

"When they play football, then they know exactly who's the best and they have they entire hierarchy down by numbers. With parkour these preconditions did not apply and the hierarchy was suddenly changed. There really were some of them that surprised me and probably each other [...] I think it was really difficult for those of them who are used to being the best at playing football." (Teacher of 14-15 year olds, at workshop)

A teacher, who taught parkour in physical education, stressed that parkour as a health education activity can include everybody and can contribute to even out physical differences:

"It's very much about being able to include these other inactive pupils and maybe build up their strength through parkour. I think there is room for everybody, if you are able to make some exercises where they can really improve their physical strength." (Teacher of 9-10 year olds) 
5.4 Competition vs. personal development

An essential value in parkour is that it is a non-competitive activity. Parkour is about challenging and developing yourself and your own skills. A girl described how she experienced that she had grown during the workshop in parkour:

"I was actually really afraid in the beginning. When you had to try something for the first time, you were really careful not to hurt yourself. But then when you had tried it a couple of times, then you got better and better. Then you worked up the courage to try even more stuff. In the end you could actually do much more than you could in the beginning." (Girl, 14 years old)

Through the different exercises the children and adolescents challenged themselves, both physically and mentally, and a lot of them transcended physical and mental barriers. However, If the exercises were not challenging enough, the children and adolescents got bored and did not learn much. A boy with previous parkour-experience evaluates his teacher's efforts:

"It was boring. It's because of our teacher, who tried to teach us parkour. He is not as good as the real instructors. I learned more when I attended real parkour training, because they have been practicing parkour for years, so they could teach me everything they know, which meant we learned more." (Boy, 10 years old)

A lot of the children and adolescents expressed that they were positively surprised by the fact that parkour was different from what they expected. The exercises and challenges turned out to be safer than they had anticipated, but in spite of this a lot of them were surprised by how difficult parkour was.

Even though parkour is about self-development and not about competing against each other, the data show that the schoolteachers used competitive elements in the way they presented parkour. A girl comments on this:

"That game we played, where we were divided into two groups, that was actually a real battle against the other group"

"And then you should collaborate within your group"

"I don't know how well the exercises were really executed, because now it was a competition." (Girls, 9-10 years old)

In the interviews many of the children indicated that the competition created a bad atmosphere among the children because they got into arguments. The competition changed the children's focus from self-development to a focus on winning the competition. And the motivation for participation changed accordingly.

\section{Discussion}

Parkour contains a high level of flexibility, which creates possibilities for differentiated teaching. In parkour it is possible to change the level of difficulty in the different exercises - 
and thereby ensure that all of the children and adolescents get challenged in ways that suit their physical and mental capabilities. In other words, the children and adolescents get the opportunity to participate at the highest level of their ability.

When planning and carrying out health promotion activities, it is generally important to consider this capacity for participation within a group or class of children and adolescents and this places demands on the person who has to teach the children and adolescents in parkour. The findings suggest that if the exercises appear too dangerous, there is a risk of excluding some of the most careful or restrained children and adolescents. Conversely, if the exercises are too easy there is a risk of children and adolescents getting bored. Accordingly, if the teachers or instructors do not take the different capacities for participation into consideration, this can have a negative effect on the children's and adolescents' participation and on the outcome of their parkour activities.

The flexibility in parkour is not as evident when it is teachers who do the parkour instructions themselves. Due to their lack of parkour-instruction skills and especially lack of parkour experience, the teachers are not as good at assessing the children's and adolescent's physical and mental capabilities. The adjustment of the exercises to accommodate all of the children and adolescents is therefore difficult for the teachers to manage, which affects the general level of participation.

Parkour contains a level of freedom which enhances opportunity for children and adolescents to be actively involved during the parkour-activities. Children and adolescents can, and must, decide for themselves how much they want to challenge themselves. During the different exercises and challenges they have to reflect on, and constantly relate to, their body and their physical capability. They have to decide whether they should push themselves further or if they should take one of the easier versions of the exercise. Thus there is a high level of self-interpretation in parkour.

The children's and adolescents' participation enhances their ownership of the learning process when they continually have to reflect on and take their own capabilities and experiences into account. Through the exercises and challenges in parkour they develop body-consciousness and knowledge about themselves and what they are capable of doing, which makes it easier for them to relate the activities they perform and the knowledge they receive to other aspects of their lives.

The level of freedom is also significant in another aspect of parkour. The fact that there are no rules about how the different exercises in parkour must be executed means that it is up to the children and adolescents to decide how they want to solve the different exercises and challenges. This means that they, have a genuine impact on the contents of the activities which in turn motivates a high level of participation.

The findings suggest that the professional instructors were especially good at involving the children and adolescents by listening to them, taking their ideas about new exercises seriously and actually putting these ideas into practice, thereby creating a sense of ownership. This ability to listen was also significant when the children and adolescents were uneasy or afraid 
of doing an exercise. In these situations the instructors created a sense of trust that seemed to motivate participation.

All of this suggests that the adult person who teaches the children and adolescents in parkour plays a significant part in generating participation. It is evident that the children and adolescents need a sparring partner who can support them when they are uneasy about an exercise and who can challenge them in a meaningful and suitable way so that they keep progressing. There were significant differences in how professional instructors and schoolteachers succeeded in being supportive sparring partners.

One of the key findings is that parkour manages to create participation among those who normally do not participate in physical education or in physical activities in general. The findings suggest that parkour's flexibility and ability to create differentiated teaching play a significant part in generating participation and creating equal possibilities for participation among all children and adolescents. This can actually contribute to minimising the physical inequalities that exist among children and adolescents.

Parkour also has the potential to contribute to new roles and structures among the participating children and adolescents in terms of physical activity and maybe even health in general. There were many examples of children and adolescents revealing new sides of themselves that not only surprised the classmates and the teacher, but also surprised the child or adolescent themselves. This has the potential to create new expectations and understandings of the children and adolescents in relation to physical activity and health which may lead to more equity in health amongst them.

The non-competitive aspect about parkour was something a lot of the children and adolescents liked. Parkour offers those children and adolescents that do not like competitive sports an alternative experience with physical activity and sport and thus has the potential to engage or re-engage children and adolescents with physical activities.

\section{Conclusion}

The study has produced two main conclusions, both of which will be important components in how parkour is to be used in school health promotion.

1) Parkour has an significant potential when it comes to generating participation in school.

2) The "power" of parkour loses significant strength when it is conducted by the briefly trained schoolteachers instead of professional parkour instructors.

Many different aspects of participation and involvement are in play with parkour and there is no doubt, that it offers something different for school health promotion. It is an alternative way of conducting and experiencing physical education and, most importantly, it has the potential of including some of the children and adolescents normally uninterested in physical activities in school. 
Unfortunately the most significant effect is found when the school uses professional parkour instructors instead of teachers - and this might be the most crucial finding of this study. The natural authenticity that comes with being an experienced and skilful traceur with the right attitude and who wears clothes with the right street credit cannot be directly transferred into the school context without losing the authenticity that seems to motivate participation. Contributing to this issue is the fact that the inexperienced schoolteachers often fail to present the core values of parkour (non-competitiveness and solidarity) to the children and adolescents. A big future challenge is to find a way to transfer parkour into the school setting without losing this authenticity.

\subsection{Strengths of the study}

One of the strengths of this study is that it explores a research field that has not been studied before. There is a dearth of existing knowledge and research on parkour as a health promotion activity and its possibilities to generate participation.

A second strength of the study is that parkour was studied within three different pedagogical contexts which gave us the opportunity to compare the contexts and to examine what worked and what did not work within them. In particular, being able to study the two different school contexts of schoolteachers in physical education and professional instructors in workshops, produced interesting results and showed us valuable perspectives for future studies.

\subsection{Limitations of the study}

The relatively few school-workshops and physical education lessons scheduled, meant that it was not possible to generate a high level of diversity in the data material. Studying parkour's possibility to generate participation within a more structured and diversified set of data material would have enabled us to elaborate even more on challenges and potentials.

If the age groups in the three studied contexts had been the same, it would have made more direct comparisons possible. However, this being a first explorative study into a new field, the goal was always to uncover significant tendencies and not to produce generalizable evidence.

\subsection{Implications for health promotion practice}

The research results of this study provide teachers and other educators with important knowledge about parkour as a health promotion activity and its possibilities to generate participation among children and adolescents. The study highlights the importance of using parkour in accordance with its core values and with the authenticity intact. Another important point for the teachers, is that they have to focus on creating flexibility and differentiation in the exercises and activities.

\subsection{Implications for further research}

This research produced several interesting perspectives for further research in parkour as a health promotion activity in school. This study focused primarily on participation, but there are other well-established focus points of health promotion and health education research that 
would be equally relevant to focus on. A research focus on action competence could be employed to produce knowledge about how parkour can motivate the development of insight, commitment, vision, critical thinking and action experiences (Jensen, 1997; Carlsson \& Simovska, 2012). Another fruitful line of research could be a closer look at the mechanisms of authenticity and especially on how authenticity is perceived by children and adolescents (Petraglia, 2009; Grabowski \& Rasmussen, 2014). The subject of inequality in health (e.g. Mohajer \& Earnest, 2010) is also a logical step for future research, as some of the data indicates that vulnerable and marginalized children and adolescents might be reached through parkour.

\section{References}

Ameel, L., \& Tani, S. (2012). Everyday aesthetics in action: Parkour eyes and the beauty of concrete walls. Emotion, Space and Society, 5, 164-173. http://dx.doi.org/10.1016/j.emospa.2011.09.003

Angel, J. (2011). Ciné Parkour - A cinematic and theoretical contribution to the understanding of the practice of parkour. Julie. Angel, London.

Atkinson, M. (2009). Parkour, Anarcho-Environmentalism, and poiesis. Journal of Sport \& Social Issues, 33(2), 169-194. http://dx.doi.org/10.1177/0193723509332582

Bavinton, N. (2007). From obstacle to opportunity: Parkour, leisure, and the reinterpretation of constraints. Annals of Leisure Research, 10(3-4), 391-412. http://dx.doi.org/10.1080/11745398.2007.9686773

Brunner, C. (2011). Nice-looking obstacles: Parkour as urban practice of deterritorialization. AI \& Society, 26(2), 143-152. http://dx.doi.org/10.1007/s00146-010-0294-2

Carlsson, M., \& Simovska, V. (2012). Exploring learning outcomes of school-based health promotion - a multiple case study. Health Education Research, 27(3), 437-447. http://dx.doi.org/10.1093/her/cys011

Clegg, J. L., \& Butryn, T. M. (2012). An existential phenomenological examination of parkour and freerunning. Qualitative Research in Sport, Exercise and Health, 4(3), 320-340. http://dx.doi.org/10.1080/2159676X.2012.693527

Gilchrist, P., \& Wheaton, B. (2011). Lifestyle sport, public policy and youth engagement: examining the emergence of parkour. International Journal of Sport Policy and Politics, 3(1), 109-131. http://dx.doi.org/10.1080/19406940.2010.547866

Grabowski, D., \& Rasmussen, K.K. (2014). Authenticity in health education for adolescents: A qualitative study of four health courses. Health Education, 114(2), 86-100. http://dx.doi.org/10.1108/HE-06-2013-0020

Hart, R. (1992). Children's participation: From tokenism to citizenship. UNICEF International Child Development Centre, Florence. 
Jensen, B. B., \& Simovska, V. (2005). Involving students in learning and health promotion processes - clarifying why? what? and how? Promotion \& Education, 12(3-4), 150-156. http://dx.doi.org/10.1177/10253823050120030114

Jensen, B.B. (1997). A Case of two paradigms within health education. Health Education Research, 12(4), 419-428. http://dx.doi.org/10.1093/her/12.4.419

Kidder, J. L. (2013). Parkour: Adventure, Risk, and Safety in the Urban Environment. Qualitative Sociology, 36(3), 231-250. http://dx.doi.org/10.1007/s11133-013-9254-8

Mager, U., \& Nowak, P. (2012). Effects of student participation in decision making at school. A systematic review and synthesis of empirical research. Educational Research Review, 7, 38-61. http://dx.doi.org/10.1016/j.edurev.2011.11.001

Mohajer, N., \& Earnest, J. (2010). Widening the aim of health promotion to include the most disadvantaged: vulnerable adolescents and the social determinants of health. Health Education Research, 25(3), 387-394. http://dx.doi.org/10.1093/her/cyq016

Nordin, L. L., Jensen, J. M., \& Simovska, V. (2010). Unges deltagelse I sundhedsfremme? Hvad siger litteraturen? Cursiv, 5, 77-101.

Peters, L.W.H., Wiefferink, C.H., Hoekstra, F., Buijs, G.J., ten Dam, G.T.M., \& Paulussen, T.G.W.M. (2009). A review of similarities between domain-specific determinants of four health behaviors among adolescents. Health Education Research, 24(2), 198-232. http://dx.doi.org/10.1093/her/cyn013

Petraglia, J. (2009). The importance of being authentic: Persuasion, narration, and dialogue in health communication and education. Health Communication, 24(2), 176-185. http://dx.doi.org/10.1080/10410230802676771

Rasmussen, J. (2004). Textual interpretation and complexity: Radical hermeneutics. Nordisk Pedagogikk, 24(3), 177-194.

Saville, S. J. (2008). Playing with fear: parkour and the mobility of emotion. Social \& Cultural Geography, 9(8), 892-914. http://dx.doi.org/10.1080/14649360802441440

Simovska, V. (2004). Student participation: a democratic education perspective - experience from the health-promoting schools in Macedonia. Health Education Research, 19(2), 198-207. http://dx.doi.org/10.1093/her/cyg024

Simovska, V. (2007). The changing meanings of participation in school-based health education and health promotion: the participants' voices. Health Education Research, 22(6), 864-878. http://dx.doi.org/10.1093/her/cym023

Sinclair, R. (2004). Participation in Practice: Making it Meaningful, Effective and Sustainable. Children and Society, 18, 106-118. http://dx.doi.org/10.1002/chi.817

Wheaton, B. (2004). Introduction: mapping the lifestyle sport-scape. In: Understanding lifestyle sports - consumption, identity and difference, Wheaton, B. (red.). Routledge, London. 
Wilson, L. (2009). Pupil participation: comments from a case study. Health Education, 109(1), 86-102.

Wistoft, K. (2010). Health Strategies and reservoirs of knowledge among adolescents in Denmark. Global Health Promotion, 17(2), 16-24. http://dx.doi.org/10.1177/1757975910365233

\section{Note}

Note 1. The ADAPT-certification is the international standard for parkour instructors, which ensures that the instructor who teaches others in parkour will do so in a knowledgeable, professional, competent and safe manner.

\section{Copyright Disclaimer}

Copyright for this article is retained by the author(s), with first publication rights granted to the journal.

This is an open-access article distributed under the terms and conditions of the Creative Commons Attribution license (http://creativecommons.org/licenses/by/3.0/). 